\title{
The influence of the spatial resolution of topographic input data on the accuracy of 3-D UV actinic flux and irradiance calculations
}

\author{
P. Weihs ${ }^{1}$, J. E. Wagner ${ }^{1}$, S. F. Schreier ${ }^{1}$, H. E. Rieder ${ }^{2,3}$, F. Angelini ${ }^{4}$, M. Blumthaler ${ }^{5}$, M. Fitzka ${ }^{1}$, G. P. Gobbi ${ }^{4}$, \\ R. Kift ${ }^{6}$, A. Kreuter ${ }^{5}$, S. Simic ${ }^{1}$, and A. R. Webb ${ }^{6}$ \\ ${ }^{1}$ Institute of Meteorology, University of Natural Resources and Life Sciences, Vienna, Austria \\ ${ }^{2}$ Institute for Atmospheric and Climate Science, ETH Zurich, Zurich, Switzerland \\ ${ }^{3}$ Department of Applied Physics and Applied Mathematics, Columbia University, New York, USA \\ ${ }^{4}$ Institute of Atmospheric Sciences and Climate, ISAC-CNR, Rome, Italy \\ ${ }^{5}$ Division for Biomedical Physics, Innsbruck Medical University, Innsbruck, Austria \\ ${ }^{6}$ School of Earth, Atmospheric and Environmental Sciences, University of Manchester, Manchester, UK
}

Correspondence to: P. Weihs (weihs@mail.boku.ac.at)

Received: 11 August 2011 - Published in Atmos. Chem. Phys. Discuss.: 5 October 2011

Revised: 3 February 2012 - Accepted: 20 February 2012 - Published: 1 March 2012

\begin{abstract}
The aim of this study is to investigate the influence of the spatial resolution of a digital elevation map (DEM) on the three-dimensional (3-D) radiative transfer performance for both spectral ultraviolet (UV) irradiance and actinic flux at $305 \mathrm{~nm}$. Model simulations were performed for clear sky conditions for three case studies: the first and second one using three sites in the Innsbruck area and the third one using three sites at the Sonnblick observatory and surrounding area. It was found that the DEM resolution may change the altitude at some locations by up to $500 \mathrm{~m}$, resulting in changes in the sky obscured by the horizon of up to $15 \%$. The geographical distribution of UV irradiance and actinic flux shows that with larger pixel size, uncertainties in UV irradiance and actinic flux determination of up to $100 \%$ are possible. These large changes in incident irradiance and actinic flux with changing pixel size are strongly connected to shading effects. The effect of the DEM pixel size on irradiance and actinic flux was studied at the six locations, and it was found that significant increases in irradiance and actinic flux with increasing DEM pixel size occurred at one valley location at high solar zenith angles in the Innsbruck area as well as for one steep valley location in the Sonnblick area. This increase in irradiance and actinic flux with increasing DEM resolution is most likely to be connected to shading effects affecting the reflections from the surroundings.
\end{abstract}

\section{Introduction}

Ultraviolet (UV) radiation belongs to the shortest wavelength range of the solar spectrum and covers only a small range (less than 10 percent) of the total energy of solar radiation. However, its significance is due to the high energy of photons in this wavelength range (e.g., Gantner, 2000). Solar UV radiation has a wavelength range between $200 \mathrm{~nm}$ and $400 \mathrm{~nm}$ and is subdivided into three spectral regions commonly referred to as UV-C (200-280 nm), UV-B (280$315 \mathrm{~nm})$ and UV-A (315-400 nm) (e.g., Commision Internationale de'l Eclairage, 1999; World Health Organization (WHO), 2002). In the last few decades interest in UV radiation has increased within the scientific community as it has been linked to a broad variety of environmental and health effects (e.g., Slaper et al., 1996; Longstreth et al., 1998; UNEP, 1998; National Radiological Protection Board, 2002; WHO, 2006). Ultraviolet radiation depends on many atmospheric factors. Among the most important atmospheric factors are clouds, total column ozone and the atmospheric aerosol load, whilst in the case of environmental factors the most important are ground reflection (e.g., surface albedo) and sky coverage due to local topography on the horizon. Various studies also show that long-term trends in UV radiation are dominated by changes in total ozone and cloudiness (e.g., Lindfors and Vuilleumier, 2005; Rieder et al., 2008, 2010; Den Outer et al., 2010). 
On a daily basis short term variability (i.e., hours or minutes) in UV radiation is related mostly to changes in cloud coverage (e.g., Calbo et al., 2005; Simic et al., 2008), whilst over the whole day variability in UV radiation is determined by changes in solar elevation (e.g., Schwander et al., 1997), aerosol optical depth (AOD) and total ozone (e.g., Feister and Grewe, 1995). Clouds often mask the influence of total ozone on UV radiation and may cancel, reduce or enhance the expected UV signal (e.g., Schafer et al., 1996; Sabburg et al., 2003; Calbo et al., 2005). In addition to total ozone and clouds, ground albedo is another significant factor influencing UV radiation, with snow cover and depth being the largest factors affecting the albedo (e.g., Blumthaler and Ambach, 1988; McKenzie et al., 1998; Weihs et al., 1999, 2001; Schmucki and Philipona, 2002), with snow albedo being highly dependent on age and type of snow (e.g., Vanicek et al., 2000; Kalliskota et al., 2000). Moreover, several studies have shown that high surface albedo can lead to an enhancement of UV radiation by up to $70 \%$ or more, with the highest enhancements observed during partly cloudy conditions (e.g., McKenzie et al., 1998; Simic et al., 2011). Atmospheric aerosols can also have a strong influence on UV radiation, as both scattering and absorption have significant wavelength dependence with a stronger effect at shorter wavelengths (e.g., Wenny et al., 1998; Reuder and Schwander, 1999). While the estimation of aerosol effects from radiation measurements in the UV-A range is not too difficult, the separation of aerosol effects is more complex in the UV$\mathrm{B}$ range where ozone absorption is dominant (e.g., Reuder and Schwander, 1999). Simultaneous measurements of AOD and ground UV performed by Krzyscin and Puchalski (1998) and Balis et al. (2004) showed that changes in AOD during a day may lead to changes in atmospheric transmission in the UV range of up to $20-30 \%$. Other measurements of the day to day variability showed that changes in AOD may result in changes of UV radiation of the order of $20 \%$ to $45 \%$ (e.g., Reuder and Schwander, 1999; Arola et al., 2007). Increasing altitude reduces the depth of the atmosphere giving a shorter path length for the solar radiation. This results in an increase in UV radiation with altitude due to a decrease in scattering and/or absorption, i.e., extinction. This is commonly referred to as the altitude effect (AE) (e.g., Blumthaler et al., 1996). Blumthaler et al. (1996) showed: (i) that a distinctly stronger altitude effect occurs in the UV-B range compared to other wavelength ranges due to tropospheric ozone and increased Rayleigh scattering at shorter wavelengths; (ii) that the altitude effect is slightly larger in winter (about $20 \%$ per $1000 \mathrm{~m}$ ) than in summer (about $15 \%$ per $1000 \mathrm{~m}$ ) due to a slight dependence on solar elevation and due to seasonal dependence of AOD, and (iii) that snow cover additionally increases the altitude effect by about $10 \%$ per $1000 \mathrm{~m}$.

Actinic flux is defined as the radiation received at a spherical surface from all solid angles $(4 \pi \mathrm{sr})$, where each photon is assigned with the same weight irrespective of the incident direction. In the present study actinic flux is not defined as the radiation received from all solid angles but only from the upper sky hemisphere ( $2 \pi \mathrm{sr})$. The fundamental idea and theory of transfer from flat to spherical surfaces is discussed in Madronich (1987) and van Weele et al. (1995). Actinic flux is needed for the calculation of photolysis rates and is therefore an elementary quantity for atmospheric photochemistry. So far only a limited number of studies report on the direct measurement of actinic flux (e.g., Nader and White, 1969; Van Weele et al., 1995; Kazadzis et al., 2000; McKenzie et al., 2001; Webb et al., 2002; Kylling et al., 2005; Thiel et al., 2008; Wagner et al., 2011). More recently numerical modeling studies, with 1-D and/or 3-D radiative transfer models, of actinic flux have been performed (e.g., Kylling et al., 2005; Thiel et al., 2008; Wagner et al., 2011), showing reasonable agreement with the measurements, especially under clear-sky conditions (agreement within 10\%). However, modeling of UV spectral actinic flux in mountainous areas, especially in the presence of snow, is complex and still poses a scientific challenge.

The most frequently used models within the scientific community are 1-D radiative transfer models. Their major advantage is the fast computation time, as most applications require only knowledge of two radiation components, irradiance and radiance. Discrete ordinate methods are frequently applied in the 1-dimensional case, and in particular the two stream methods (i.e., radiation is considered in two directions: upward and downward) are suitable for many applications, e.g., numerical weather prediction models or climate models. In general one can state that radiative transfer for clear-sky conditions and over flat terrain is well understood and that established solutions to deal with cloudiness are available (e.g., Smith et al., 1992; Krotkov et al., 1998; Badosa et al., 2007).

For complex terrain (e.g., mountainous terrain) things are more complicated and the importance of specific influencing factors is hard to estimate as the topography produces a nonhomogeneous radiation field due to shading effects and horizon effects. These factors will not be fully taken into account in estimating the radiation incident on a pixel level. Factors such as the "altitude effect", which are well understood for flat terrain, are also more difficult to deal within a complex terrain as the terrain determines the snow distribution. Snow will disappear first at lowest altitudes and southern oriented slopes whilst it correspondingly remains (or may even accumulate) at higher altitudes and north oriented slopes. Large differences in UV irradiance due to difference in surface albedo between snow covered and snow free mountainous environment was found by McKenzie et al. (1998), Pachard et al. (1999) Weihs et al. (2001) and Simic et al. (2008, 2011). Similar complexity is also found for other terrains and Smolskaia et al. (1999) measured differences of up to $10 \%$ in UV irradiance between snow covered ice and open water in Antarctica, Ricchiazzi and Gaultier (1998) found a large drop in planetary albedo from a maximum several $\mathrm{km}$ inland from Palmer station (Antarctica) to a minimum about $2 \mathrm{~km}$ off the 
coast. Kylling et al. (2000) found relatively low maximum values of average effective winter albedo $(0.57$ at $320 \mathrm{~nm}$ and 0.78 at $450 \mathrm{~nm}$ ) at Troms $\varnothing$ (Norway), due to the contribution of open water at the coast. Exact knowledge of large-scale surface albedo is a crucial factor for accurate model calculations as areas around the measurement station might still contribute significantly - i.e., with a contribution larger than the measurement uncertainty - to the measured UV. So far there are few studies dealing with this problem and the results for the "radius of importance" differ quite strongly. Degünther et al. (1998) state that contributions from outside a radius of $40 \mathrm{~km}$ around a measurement station can reach up to $3 \%$, while Smolskaia et al. (1999) refer to a radius of importance of only $2.5 \mathrm{~km}$ and Wagner et al (2011) estimated, for the case studies in the Innsbruck area, the radius of importance for actinic flux at $5 \mathrm{~km}$.

To address such complexity (e.g., complex terrain, varying snowfields, 3-D clouds) 3-D radiative transfer models are commonly used either for direct radiative transfer calculations (which are often computationally expensive) or more commonly for validation runs of the 1-D radiative transfer model output. The most popular technique for 3-D radiative transfer calculations is the Monte-Carlo method as it allows for consideration of all relevant processes without simplification. 3-D radiative transfer models allow 3-D clouds, complex topography and inhomogeneous surface albedo to be fully taken into account. For a detailed review of radiative transfer with 1-D and 3-D models we refer to Mayer and Kylling (2005), Cahalan et al. (2005) and Mayer et al. (2010). To the knowledge of the authors no previous study has addressed the influence of the digital elevation map (DEM) resolution on the calculation accuracy of 3-D models.

Therefore, within the present study the influence of the spatial resolution of the DEM on 3-D radiative transfer model performance for UV irradiance and actinic flux is analyzed in great detail for three case studies of regions with complex terrain (mountainous/alpine) in Austria. The uncertainties are quantified and their causes are analysed.

\section{Methods and data}

Firstly the effect of the DEM resolution on altitude, horizon and proportion of shaded pixels is described, (Sect. 3.1). Simulations of possible effects on UV irradiance and actinic flux are performed with a 1-D model.

Secondly - using a 3-D radiative transfer model - we investigate the geographical distribution of UV irradiance and actinic flux and the influence thereon of DEM resolution.

Thirdly, 3-D radiative transfer simulations of irradiance and actinic flux are performed at selected locations using the different DEM resolutions and are compared to ground based measurements.

The present investigations were only performed for clear sky conditions, and to reduce computational costs model cal- culations were only performed at $305 \mathrm{~nm}$. With $305 \mathrm{~nm}$ being selected as it shows similar behaviour to erythemal UV, and has a strong photobiological efficiency.

\subsection{Locations and measurement data}

The ground based measurements of UV irradiance and UV actinic flux were made during three field campaigns in 2007 and 2008 (Wagner et al., 2010, 2011). The first two campaigns took place near Innsbruck, Austria in late summer 2007 (2 to 22 September and late winter 2008 (19 February to 6 March). The third campaign took place in the Sonnblick area in spring 2008 (29 April to 9 May). During the first two campaigns measurements of UV and visible radiation, with Bentham DTM 300 spectroradiometers, were performed at the two stations Innsbruck and Hafelekar, while at a third site, Lans, measurements were made with a Bentham DM 150. During the third campaign measurements were made at three stations Bodenhaus and Sonnblick (using Bentham DM 150 spectroradiometers) and Kolm-Saigurn (using a Bentham DTM 300 spectroradiometer). In the present investigation data taken at the following dates and times were used: 24 February 08:20 and 12:32 UTC for the Innsbruck area and 7 May 2008 12:08 UTC for the Sonnblick area. These specific days were selected because they are clear sky days. The time of the day of the measurements selected correspond at noon to the overpass time of the AURA satellite (with OMI instrument onboard which may provide information on the atmosphere (mainly column ozone and aerosol load)). The validation of the OMI retrieval of ground UV using ground UV measurements was performed in a previous study (Wagner et al., 2010). One case study with low solar elevation (24 February, 08:20 UTC) was however added in order to investigate the effect of DEM resolution on UV also for low solar elevation. An overview of the station locations and characteristics are provided in Tables 1 and 2 and Figs. 1 and 2, with further details given in Wagner et al. $(2010,2011)$.

\subsection{Model setup}

\subsubsection{1-D radiative transfer model}

Sensitivity studies were performed with the 1-D radiative transfer model SDISORT from the LibRadtran package (Mayer and Kylling, 2005). The SDISORT radiative transfer solver was used as described in Dahlback and Stamnes (1991) and run using six streams. UV irradiance spectra and actinic flux were calculated with one nm steps and these convolved with a triangle slit function with a FWHM (full width at half maximum) of one nm. In the simulations the ATLAS 3 extraterrestrial solar spectrum (with $1 \mathrm{~nm}$ resolution) was used and sun-earth distance corrections were applied. The AFGL (Air Force Geophysics Laboratory) mid-latitude profiles of Anderson et al. (1986) were used for ozone, temperature and air pressure. The ozone profile was scaled 
Table 1. Input parameters for model calculations (altitude in [m], solar zenith angle (sza) in $\left[^{\circ}\right]$, time [UTC], total ozone column (ozone) in [DU], albedo, Angstrøm exponent and coefficient $(\alpha$ and $\beta$ ) and height of (snowline) in [m]. Simulations were performed for clear sky conditions.

\begin{tabular}{lccc}
\hline Input parameters [units] & 24 Feb 2008 & 24 Feb 2008 & 7 May 2008 \\
\hline & Innsbruck & Innsbruck & Sonnblick \\
altitude [m] & 616 & 616 & 3106 \\
sza [ ${ }^{\circ}$ ] & 56.91 & 70.0 & 32.77 \\
time [UTC] & $12: 30$ & $08: 20$ & $12: 00$ \\
ozone [DU] & 265 & 265 & 345 \\
average albedo & 0.32 & 0.32 & 0.58 \\
$\alpha$ & 1.1 & 1.1 & 1.08 \\
$\beta$ & 0.02 & 0.02 & 0.0008 \\
snowline [m] & 1300 & 1300 & 1400 \\
\hline
\end{tabular}

Table 2. Information on ground-based stations used in this study.

\begin{tabular}{lcccc}
\hline Measurement site & instrument & latitude & longitude & altitude \\
\hline Innsbruck & BENTHAM DTM300 & $47.26428^{\circ} \mathrm{N}$ & $11.38511^{\circ} \mathrm{E}$ & $616 \mathrm{~m}$ a.s.l. \\
Lans & BENTHAM DM150 & $47.24544^{\circ} \mathrm{N}$ & $11.43175^{\circ} \mathrm{E}$ & $833 \mathrm{~m}$ a.s.l. \\
Hafelekar & BENTHAM DTM300 & $47.31267^{\circ} \mathrm{N}$ & $11.38386^{\circ} \mathrm{E}$ & $2275 \mathrm{~m}$ a.s.l. \\
Bodenhaus & BENTHAM DM150 & $47.09947^{\circ} \mathrm{N}$ & $12.99575^{\circ} \mathrm{E}$ & $1296 \mathrm{~m}$ a.s.l. \\
Kolm-Saigurn & BENTHAM DTM300 & $47.06822^{\circ} \mathrm{N}$ & $12.98406^{\circ} \mathrm{E}$ & $1600 \mathrm{~m}$ a.s.l. \\
Sonnblick & BENTHAM DM150 & $47.05389^{\circ} \mathrm{N}$ & $12.95694^{\circ} \mathrm{E}$ & $3106 \mathrm{~m}$ a.s.l. \\
\hline
\end{tabular}

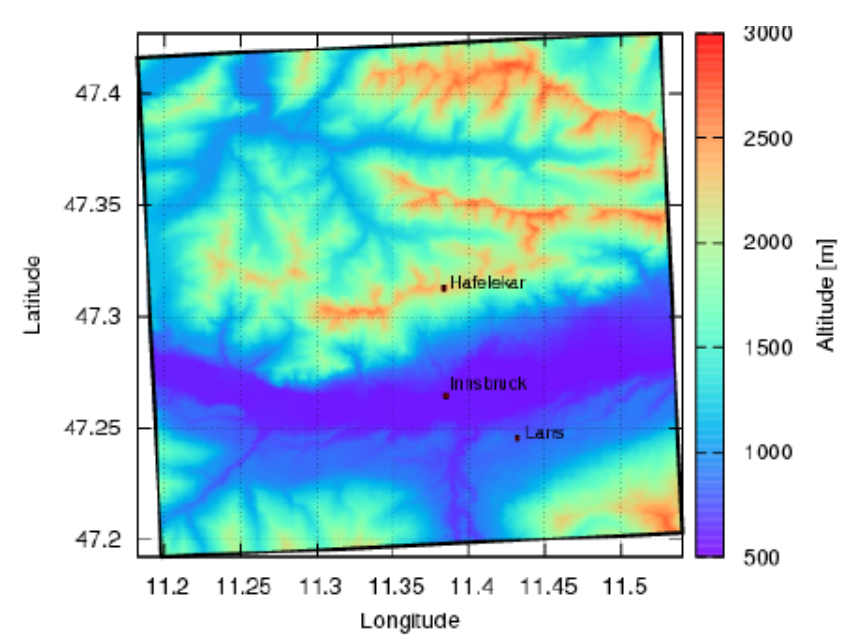

Fig. 1. The digital elevation map used within the 3-D-radiative transfer model for the Innsbruck section. The three measurement sites within this study region are also shown.

according to total column ozone derived from Brewer measurements at Sonnblick observatory. The aerosol extinction profile was measured by a polarization lidar and scaled accordingly to AOD, calculated according to the Langley extrapolation method. We ran the SDISORT program using the input information indicated in Table 1.

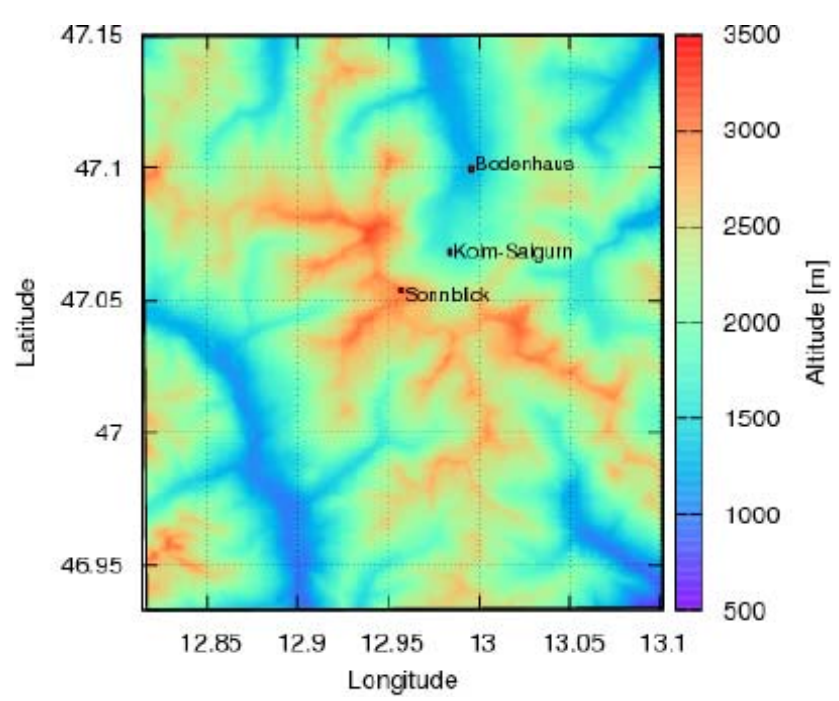

Fig. 2. The digital elevation map used within the 3-D-radiative transfer model for the Sonnblick section. The three measurement sites within this study region are also shown.

\subsubsection{3-D radiative transfer model}

In this study radiative transfer calculations were performed using the GRIMALDI 3-D Monte Carlo Model (Scheirer and Macke, 2001, 2003). The GRIMALDI model used is an 
updated version, adapted to mountainous terrain, which allows the use of a digital elevation map with tilted surfaces (see Figs. 1 and 2). Light is considered in the model as an ensemble of photons which are allowed to travel through the model domain until an interaction (scattering and/or absorption) occurs. Polarization is not considered as after the interaction process a new direction and weight (due to partial absorption) is applied. The model input parameters were the same as for the 1-D model calculations (Table 1). As the aim of this study is to analyze the influence of the spatial resolution of the DEM on the model performance, the model was run using 5 different resolutions $(50 \mathrm{~m}, 100 \mathrm{~m}, 200 \mathrm{~m}, 400 \mathrm{~m}$, $800 \mathrm{~m}$ ). The analysis was performed for the two areas where measurement campaigns had been performed (the Innsbruck area and the Sonnblick area). The Innsbruck model domain has the size of $x=26 \mathrm{~km}, y=25 \mathrm{~km}, z=40 \mathrm{~km}$ and the Sonnblick model domain has the size of $x=21.75 \mathrm{~km}$, $y=24.1 \mathrm{~km}, z=40 \mathrm{~km}$. We first run the model in order to investigate the geographical distribution of UV irradiance and actinic flux for the two model domains (see Sect. 3.2.1). We then investigated the impact of change in pixel size on irradiance and actinic flux at selected pixels (see Sect. 3.2.2). In this case, we run the model in the same way using the same model domain, setting however the inclination of the selected pixels to the horizontal in order to be comparable to the measurements.

\section{Geometrical problems arising in 3-D model calculations: pixel discontinuity}

Recently Mayer et al. (2010) pointed out the problem of possible discontinuities between quadratic pixels (pixel is defined as a quadratic plane with a defined orientation and inclination determined (by interpolation) using the DEM altitudes at the 4 plane corners). To avoid such problems Mayer et al. (2010) suggest either applying bi-linear interpolation between four grid points or the use of triangular grid point repartition instead of a quadratic grid point repartition. However, these approaches are not "perfect" as additional problems arise for the calculation of irradiance (i.e., power per unit area of electromagnetic radiation at a plane surface) or actinic flux (i.e., power per unit area of electromagnetic radiation at the surface of a sphere), but Mayer et al. (2010) supply a method to convert radiance on inclined to horizontal planes. However this method suffers from spikes since the equation includes the quantity $(1 / \cos ($ sza) $)$ which may tend towards infinity for large solar zenith angles. Therefore, Mayer et al. (2010) suggest the use of backward Monte Carlo modeling to solve this issue.

In the present study correction methods for irradiance and for actinic flux simulations are used to address possible topographical discontinuities between neighboring pixels. The correction methods make use of additional simulations of the direct and diffuse irradiance under "controlled conditions" (i.e., no atmosphere in the model) to convert photon numbers into actinic flux or irradiance. The correction method for the irradiance calculations is described in detail in Appendix A. and for actinic flux in Wagner et al. (2011).

\section{Uncertainty estimations of 3-D model calculations}

Model runs were performed with $10^{9}$ photons, to ensure numerical uncertainty is below $5 \%$. Another model uncertainty arises from the assumption of isotropy for the diffuse radiance distribution (Eqs. (11) and (12) of Appendix). According to Gueymard (2008) the uncertainty arising from this assumption may be up to $5 \%$. This results in a maximum uncertainty in the calculation method of $10 \%$ if we take both into account. This uncertainty in the calculations will affect the relative differences in irradiance and actinic flux obtained for the different DEM resolutions.

When model results are compared with ground measurements then the uncertainties in the model input parameter have to be taken into account. The model input parameters were the same for both the 3-D and 1-D model calculations (see Table 1). The first source of error lies in the albedo estimation as the snow line was estimated using reference points on photographs accurate to about $\pm 50 \mathrm{~m}$. The reflectivity of the snow was set to 0.7 which can be in error by up to $30 \%$ (Weihs and Webb, 1997) and therefore could result in uncertainty in UV irradiance and actinic flux of up to $4 \%$. Total ozone as measured at the Sonnblick observatory was used in the model. From results of Schmalwieser et al. (2003) it can be estimated that the resulting on site modelling error, from the measurement uncertainty in column ozone, should not exceed $1 \%$. Finally, also the accuracy of the aerosol optical depth has to be considered, but as the aerosol optical depth was small we expect uncertainties not larger than $\pm 3 \%$ (e.g., Weihs et al., 1999).

\section{3-D Model validation}

During the adaptation and testing of the 3-D model, the 1-D model calculations were compared to the 3-D model calculations. The GRIMALDI model was run without topography at different altitudes and good agreement (within $\pm 5 \%$ ) (Wagner et al., 2011) with the 1-D-model was obtained. This demonstrates that the 1-D radiative transfer model may be used in conjunction with the 3-D model for sensitivity simulations as long as no topography effects are involved.

Wagner et al. (2010, 2011) compared the 3-D spectral UV irradiance and actinic flux calculations with the ground measurements made with spectrometers during the two measurement campaigns performed in the Innsbruck and Sonnblick regions (see Sect. 2.1). These showed a maximum discrepancy between the 3-D-model simulations and measurements of up to $13 \%$ for irradiance and up to $25 \%$ for actinic flux in the UVB. It should however be kept in mind that the accuracy 
of spectral UV irradiance and spectral actinic flux measurements are estimated to be in the region of $\pm 5 \%$ (Bais et al., 2001) and $\pm 10 \%$ (Bais et al., 2003) respectively. For further details on the 3-D radiative transfer model and model validation we refer to Wagner et al. $(2010,2011)$.

\section{Results}

\subsection{Effect on Parameters of digital elevation map resolution}

\subsubsection{Altitude}

In general, DEMs with larger pixel size (lower resolution) lead to an underestimation of the model altitudes of the observation sites at higher altitudes and to an overestimation of the altitude of observation sites at lower altitudes, especially in cases of very uneven topography such as deep valleys with steep sides. So for the case of Kolm Saigurn, located in a narrow valley increasing the DEM pixel size resulted in an overestimation in altitude which increases from $1594 \mathrm{~m}$ at $50 \mathrm{~m}$ resolution to $2146 \mathrm{~m}$ at $800 \mathrm{~m}$ resolution. At the higher sites of Sonnblick and Hafelekar, a decrease in altitude from $3054 \mathrm{~m}$ to $2849 \mathrm{~m}$ at Sonnblick and from $2278 \mathrm{~m}$ to $2015 \mathrm{~m}$ at Hafelekar with increasing DEM pixel size was seen. At the other stations the dependence of pixel altitude on digital elevation map resolution is less than $50 \mathrm{~m}$.

The altitude effect on UV was simulated with the SDISORT RT code by changing the surface elevation input parameter whilst keeping all other parameters constant. At Kolm Saigurn a resulting increase in UV irradiance of up to $4 \%$ at $305 \mathrm{~nm}$ at a solar zenith angle of 57 degrees was found, and the corresponding increase in actinic flux was of the same order of magnitude (up to $4.5 \%$ ). The decrease in altitude at lower DEM resolution, at the Sonnblick and Hafelekar stations, led to decreases in simulated UV irradiance and actinic flux of up to $2 \%$ at Hafelekar and of up to $1.5 \%$ at Sonnblick. These results are similar to calculations performed at other solar zenith angles, where changes in UV of the same order of magnitude were obtained.

\subsubsection{Changes to the horizon}

From the model results it can also be seen that the modeled sky coverage decreases as the DEM resolution decreases. To obtain these results the horizon was first calculated for each azimuth angle and each pixel of the respective DEM and then averaged over all the azimuth angles using Eq. (11). The change in horizon is largest for the valley station Kolm Saigurn with the horizon covering around $35 \%$ of the sky when using the $50 \mathrm{~m}$ resolution DEM, decreasing to $21 \%$ for the $800 \mathrm{~m}$ resolution DEM. The decrease in sky obstruction as a function of increasing DEM pixel size is at around $3 \%$ to $5 \%$ for Bodenhaus, Hafelekar and Sonnblick and is less than $2 \%$ for Innsbruck and Sonnblick. A rough estimate of the effect of the horizon on global irradiance and on actinic flux was made using the assumption of an isotropic diffuse radiance distribution. The results were obtained by multiplying the calculated diffuse component using a 1-D RT model with the correction factors from Eq. (11) (and then adding it to the direct irradiance in order to obtain the global irradiance) and by using the same calculation method for the actinic flux by multiplying the diffuse actinic flux with the percentage of the sky upper hemisphere which is visible. Results for UV irradiance for a solar zenith angle of 57 degrees are shown in Fig. 3. The values are normalized to the simulations using the $50 \mathrm{~m}$ resolution DEM. A strong increase in irradiance and actinic flux (not shown here) of up to $12 \%$ is found for Kolm Saigurn, whilst for the other stations the changes to the horizon only lead to uncertainties in irradiance and actinic flux determination of less than $5 \%$.

The obstruction of the sun by the surroundings leads to shading and this can result in large decreases in global irradiance. Figure 4 shows the decrease in the proportion of shaded pixels for the three simulated conditions similar to the one of our case studies (for the digital elevation maps of the areas around Innsbruck and Sonnblick).

At large solar zenith angles such as 70 degrees, which is approximately the height of the sun at noon in winter, the effect is much larger. The proportion of the pixels that are shaded decreases from $33 \%$ at DEM of $\leq 100 \mathrm{~m}$ to $7 \%$ for the $800 \mathrm{~m}$ DEM resolution. The calculations performed for the Sonnblick area for a solar zenith angle near 30 degrees show $9 \%$ of pixels shaded for the $50 \mathrm{~m}$ DEM resolution which decreases to less than $1 \%$ for the 400 or 800 m DEM resolution. We also compared the proportion of the pixels that are shaded in the Innsbruck area to the shaded pixels in the Sonnblick area for the same solar positions (not shown in figure) and for $50 \mathrm{~m}$ DEM resolution. For a solar zenith angle of 57 degrees roughly $19 \%$ of the pixels are shaded in the Sonnblick region (compared to $14 \%$ for the Innsbruck area) and for a solar zenith angle of 70 degrees already $53 \%$ of the Sonnblick pixels are shaded (Innsbruck $32 \%$ ). This clearly shows that a more pronounced topography (like in the Sonnblick area) leads to more shading.

Shading will strongly change the reflection of surrounding pixel and a strong effect on the actinic flux may therefore be expected.

\subsection{Influence of digital elevation map resolution on accuracy of UV irradiance and actinic flux calculations}

\subsubsection{Influence on geographical distribution of UV}

The geographical distribution of global UV irradiance and global actinic flux at $305 \mathrm{~nm}$ is shown for the area of Innsbruck for a solar zenith angle of 70 degrees and an azimuth angle of 131 degrees (sun from south-east) (see Figs. 5-8). Figures 5 and 6 show the 3-D model calculations for a DEM 


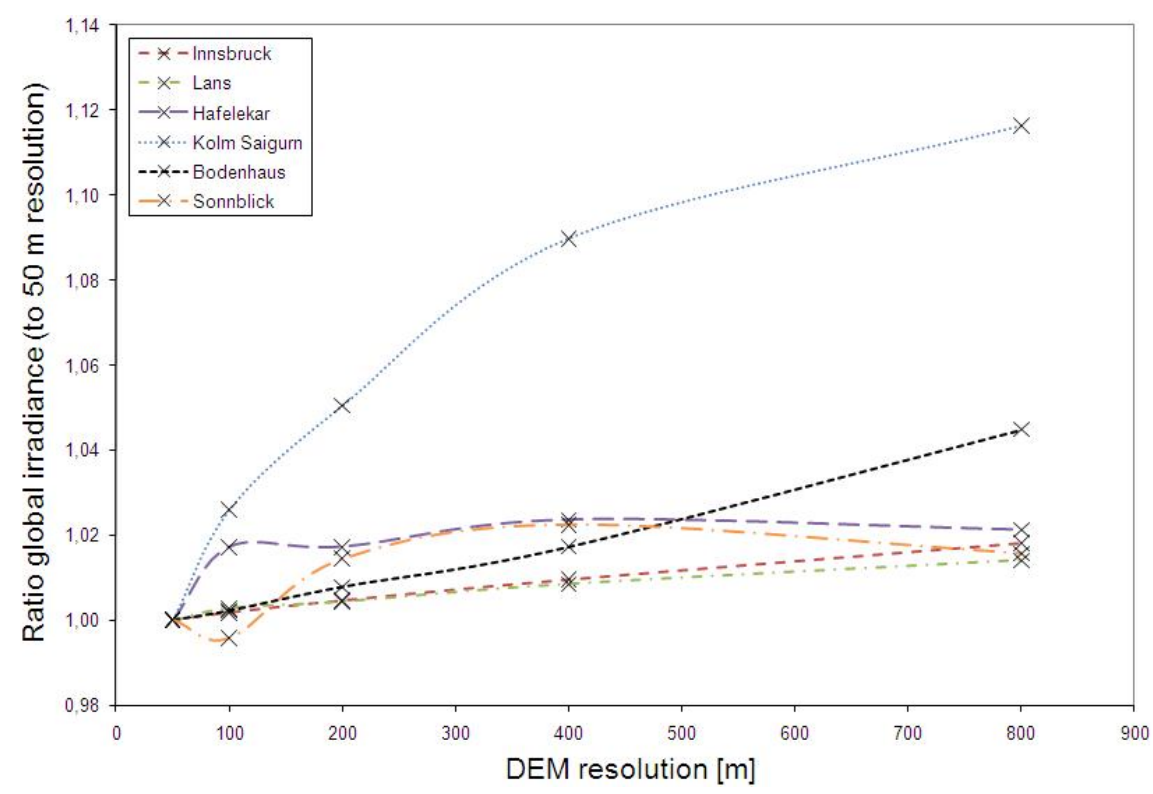

Fig. 3. Influence of changes in the horizon using different resolution DEMs on global irradiance. The change in global irradiance at $305 \mathrm{~nm}$ is shown as a function of the respective DEM resolution (which has an effect of changing the modelled horizon at the various sites). The results are normalised to the results of the $50 \mathrm{~m}$ DEM. Simulations were performed with a 1-D radiative transfer model by multiplying irradiance with the error factor due to sky coverage of the horizon (Appendix Eq. (11)). Solar zenith angle is 57 degree.

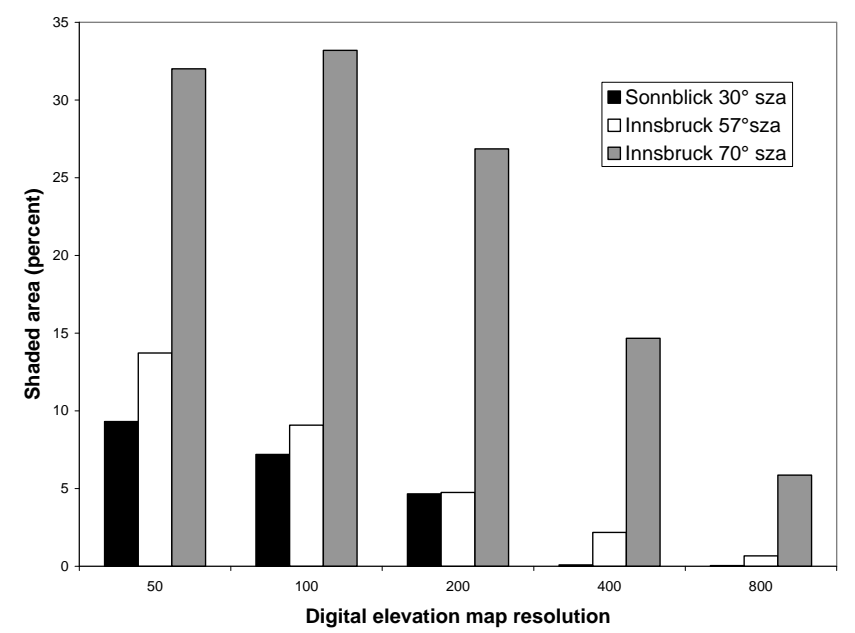

Fig. 4. Overview of the shaded areas as a function of the digital elevation map resolution. The simulations were performed using the digital elevation maps of the Innsbruck and Sonnblick regions. For the "Innsbruck" simulations, solar zenith angles of 57 and 70 degree were used and for the "Sonnblick" simulations a solar zenith angle of 30 degrees was used.

resolution of $50 \mathrm{~m}$ while Figs. 7 and 8 show the 3-D model calculations for $800 \mathrm{~m}$. In the irradiance and actinic flux calculations the inclination and orientation of the respective pixels were taken into account. Therefore the results are not comparable to those for irradiance and actinic flux on horizontal pixels (see Sect. 3.2.2).



Fig. 5. 3-D radiative transfer simulation of the $305 \mathrm{~nm}$ irradiance on 24 February 2008 08:20 UTC (70 degree solar zenith angle) using a DEM with $50 \mathrm{~m}$ resolution for the Innsbruck area.

A strong shading effect on the irradiance and actinic flux is found, as the increase in irradiance and actinic flux between shaded and non shaded pixels may be as high as $100 \%$. The ratio of the $800 \mathrm{~m}$ DEM calculations to the $50 \mathrm{~m}$ DEM calculations was determined for each pixel (Figs. 9 and 10) and was found to be between 0.3 and 2. This means that 


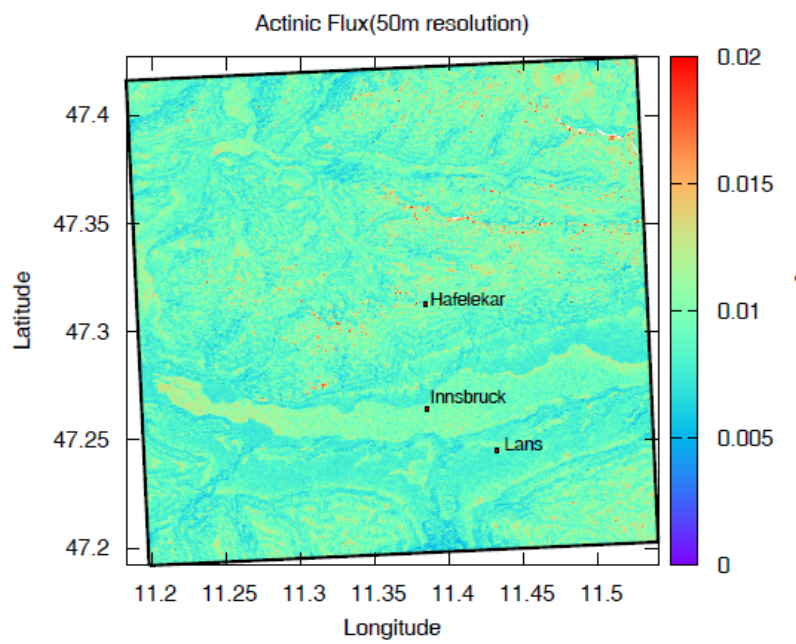

Fig. 6. 3-D radiative transfer simulation of the $305 \mathrm{~nm}$ actinic flux on 24 February 2008 08:20 UTC (70 degree solar zenith angle) using a DEM with $50 \mathrm{~m}$ resolution for the Innsbruck area.

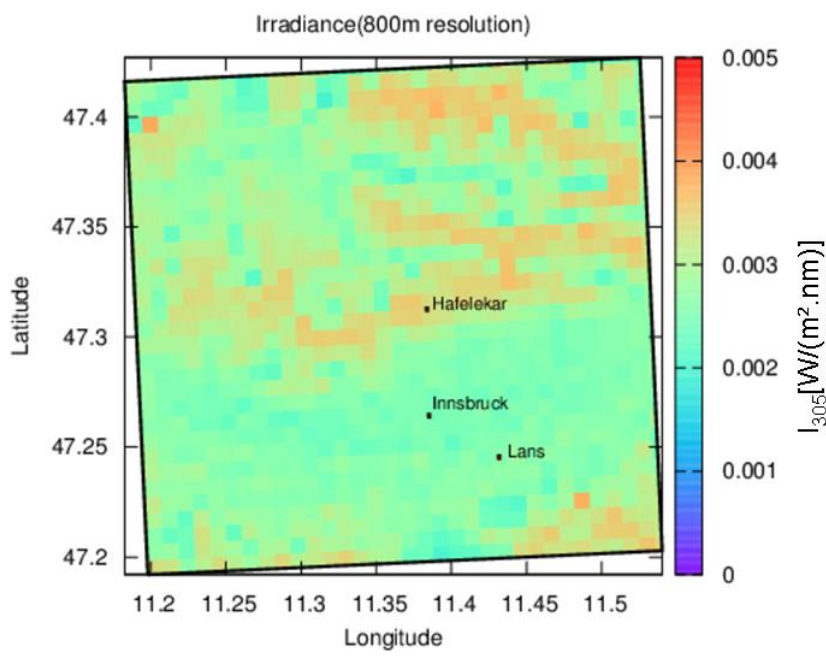

Fig. 7. 3-D radiative transfer simulation of the $305 \mathrm{~nm}$ irradiance on 24 February 2008 08:20 UTC (70 degree solar zenith angle) using a DEM with $800 \mathrm{~m}$ resolution for the Innsbruck area.

calculations made with the $800 \mathrm{~m}$ DEM may be wrong by $100 \%$ for a given location. The explanation of this large discrepancy lies first in shading effects, and second in the different inclinations and orientations of the $50 \mathrm{~m}$ pixels and corresponding $800 \mathrm{~m}$ pixels.

\subsubsection{Influence on UV irradiance incident on horizontal planes at the selected stations}

The influence of the DEM resolution on the UV irradiance at the selected stations Innsbruck, Lans, Hafelekar, Bodenhaus, Kolm Saigurn and Sonnblick was analyzed. For this purpose In the three case studies, all stations are in direct

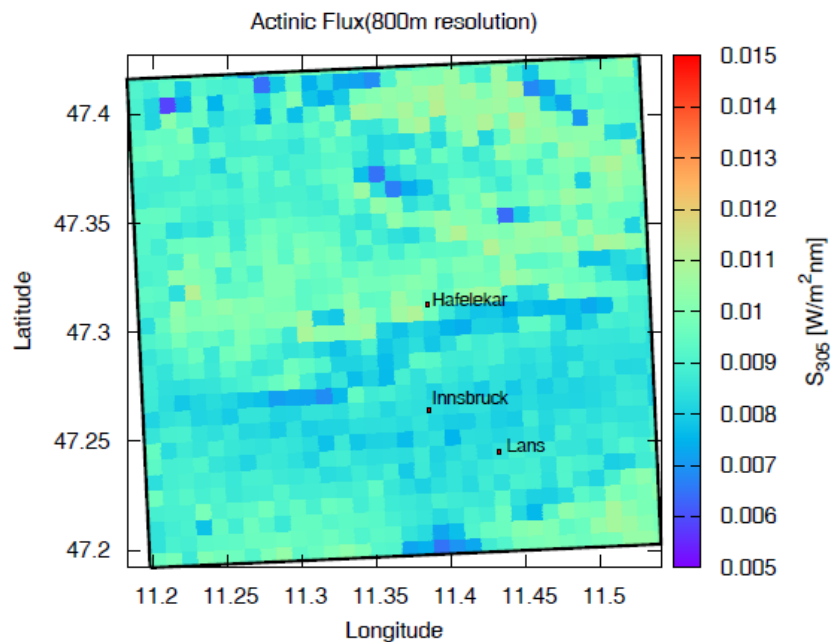

Fig. 8. 3-D radiative transfer simulation of the $305 \mathrm{~nm}$ actinic flux on 24 February 2008 08:20 UTC (70 degree solar zenith angle) using a DEM with $800 \mathrm{~m}$ resolution for the Innsbruck area.

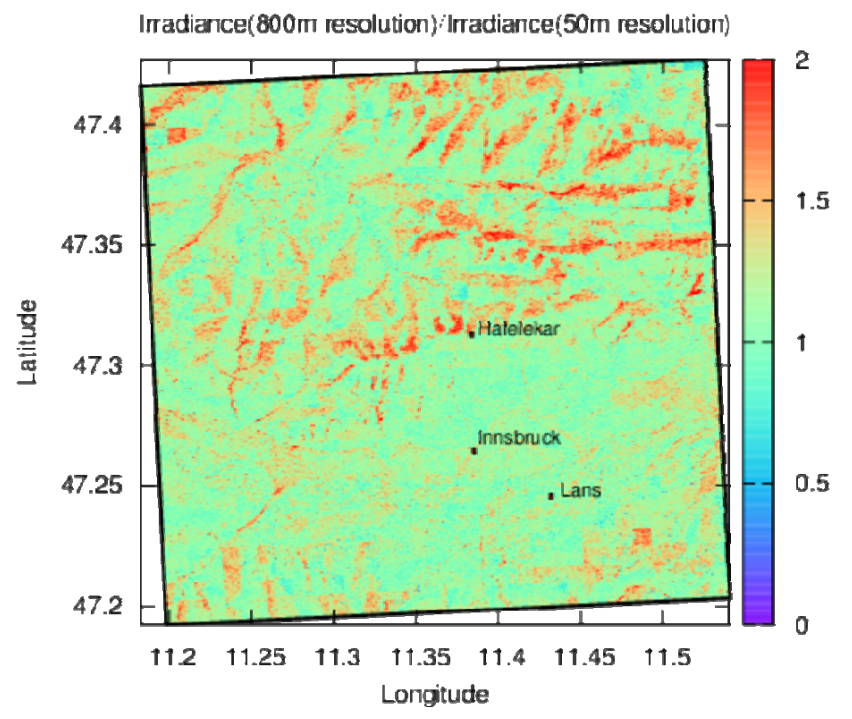

Fig. 9. Ratio of 3-D model irradiance calculation using the $800 \mathrm{~m}$ DEM to 3-D model irradiance calculation using the $50 \mathrm{~m}$ DEM. Calculations were performed at $305 \mathrm{~nm}$.

sunlight. Model runs were performed for time, date and location as given in Table 1. Figure 11 to 13 show the 3-D model simulations represented by the shapes with the corresponding error bar calculation uncertainty (see Sect. 2.2.2) and the measurements with the corresponding measurement uncertainties indicated by the coloured areas. If there is an intersection between 3-D model error bar and the measurement uncertainty area we can state that there is an agreement between measurement and model. This is achieved at the three stations for all three case studies except for the $50 \mathrm{~m}$ resolution calculation for Kolm. 


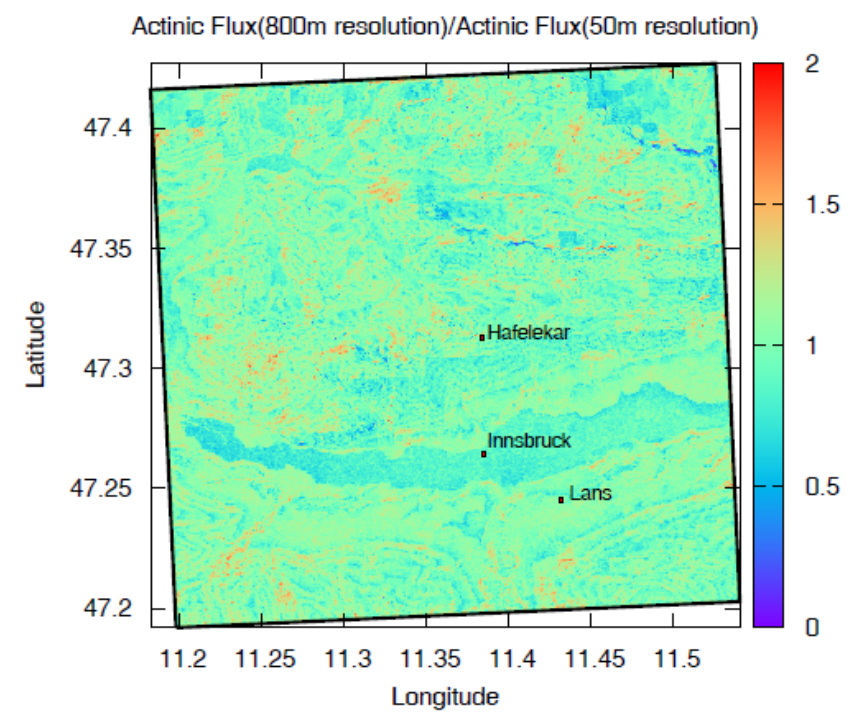

Fig. 10. Ratio of 3-D model actinic flux calculation using the $800 \mathrm{~m}$ DEM to actinic flux calculation using the $50 \mathrm{~m}$ DEM. Calculations performed at $305 \mathrm{~nm}$.

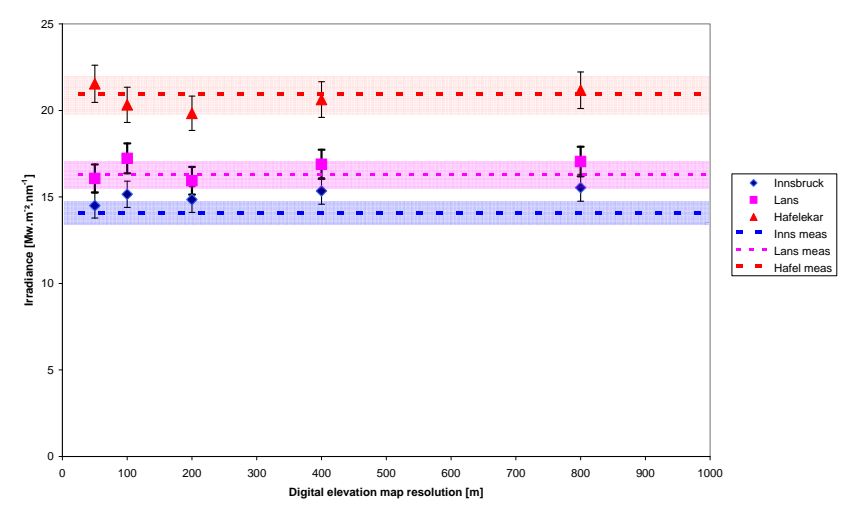

Fig. 11. Modeled 3-D UV irradiance calculations $(305 \mathrm{~nm}$ ) for 24 February, 12:30 UTC as a function of DEM resolution. Dotted lines show the measurements which correspond to the locations and the time of calculation. Solar zenith angle is 56.91 degree. The shapes show the model results (diamond = Innsbruck, square = Lans, triangle $=$ Hafelekar $)$ The error bars show the accuracy of the model simulations $( \pm 5 \%)$. The coloured areas around the lines of measurements indicate the measurement uncertainty $(= \pm 5 \%)$.

We also can only affirm that there is a statistical significant difference between two calculations performed with two different DEM pixel size if there is no overlap of their error bars. Here we will assume that the $50 \mathrm{~m}$ pixel size calculation is the most accurate and it will be taken as a reference. Figure 11 shows the UV irradiance at 12:30 UTC on 24 February for the stations Innsbruck, Lans and Hafelekar. The calculated UV irradiance does not show any large effect from DEM resolution changes. The small fluctuations of the simulated UV irradiance are within the model calculation accuracy even at

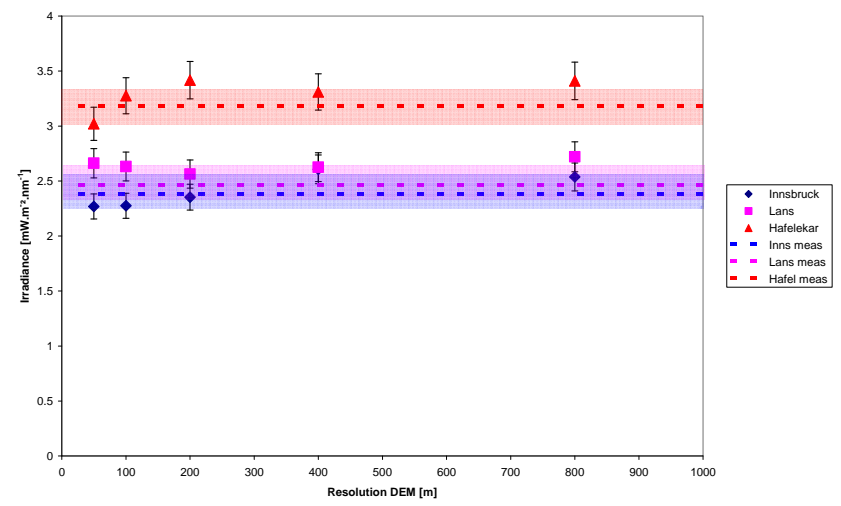

Fig. 12. Modeled 3-D UV irradiance $(305 \mathrm{~nm}$ ) calculations for 24 February, 08:20 UTC as a function of DEM resolution. Dotted lines show the measurements (interpolation of measurements before and after 08:20 UTC) which correspond to the locations and the time of calculation. Solar zenith angle is 70.0 degree. The shapes show the model results (diamond = Innsbruck, square = Lans, triangle $=$ Hafelekar $)$ The error bars show the accuracy of the model simulations $( \pm 5 \%)$. The coloured areas around the lines of measurements indicate the measurement uncertainty $(= \pm 5 \%)$.

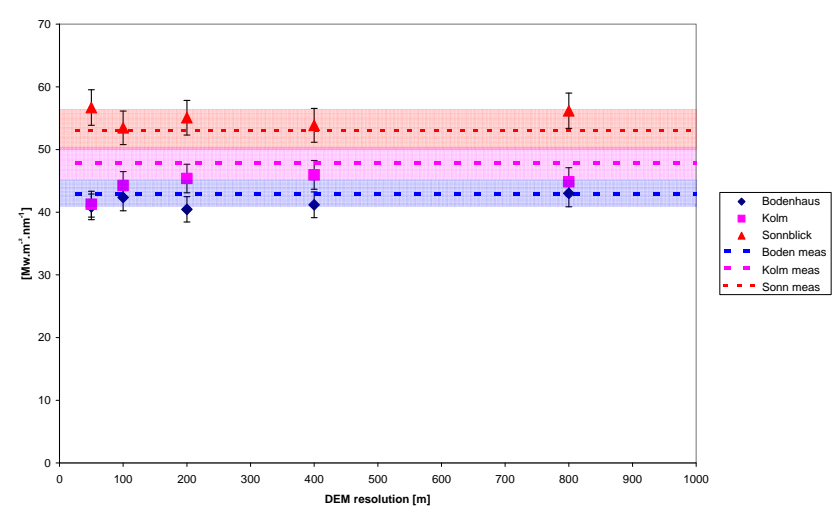

Fig. 13. Modeled 3-D UV irradiance $(305 \mathrm{~nm})$ calculations for 7 May, 12:00 UTC as a function of DEM resolution. Dotted lines show the measurements which correspond to the locations and the time of calculation. Solar zenith angle is 32.77 degree. The shapes show the model results (diamond $=$ Bodenhaus, square $=$ Kolm Saigurn, triangle $=$ Sonnblick). The error bars show the accuracy of the model simulations $( \pm 5 \%)$. The coloured areas around the lines of measurements indicate the measurement uncertainty $(= \pm 5 \%)$.

Innsbruck where the increase in UV irradiance with increasing pixel size is of the order of $4 \%$ and is still not greater than the model uncertainty. Figure 12 shows simulations of the UV irradiance for 24 February 08:20 UTC and for the five different DEM resolutions. There seems to be an influence of increasing pixel size on UV at Innsbruck for the $400 \mathrm{~m}$ and $800 \mathrm{~m}$ DEM resolution and at Hafelekar for the DEM pixel size larger than $100 \mathrm{~m}$. The simulations show UV values in Innsbruck higher than the $50 \mathrm{~m}$ resolution case by $14 \%$ and $11 \%$ at $400 \mathrm{~m}$ and $800 \mathrm{~m}$ pixel size respectively and UV 


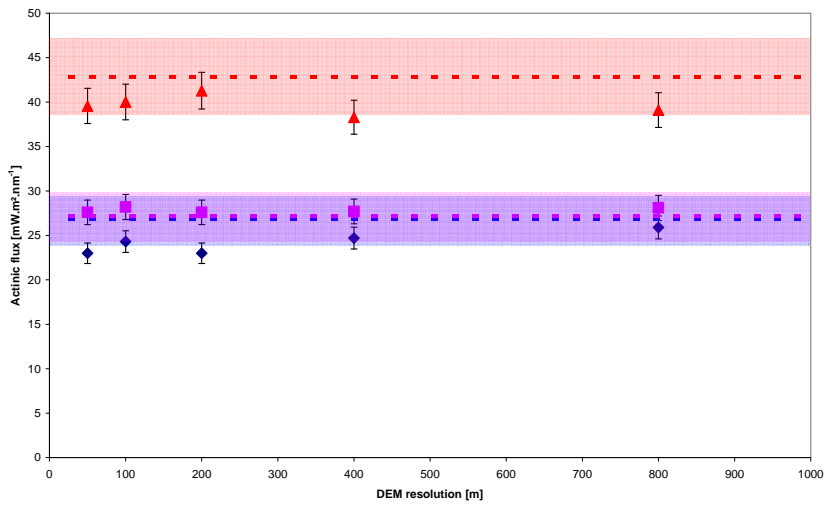

Fig. 14. Modeled 3-D UV Actinic $(305 \mathrm{~nm})$ calculations for 24 February, 12:30 UTC as a function of DEM resolution. Dotted lines show the measurements which correspond to the locations and the time of calculation. Solar zenith angle is 56.91 degree. The shapes show the model results (diamond = Innsbruck, square $=$ Lans, triangle $=$ Hafelekar). The error bars show the accuracy of the model simulations $( \pm 5 \%)$. The coloured areas around the lines of measurements indicate the measurement uncertainty $(= \pm 10 \%)$.

values at Hafelekar higher by $12 \%$ at DEM pixel sizes larger than $100 \mathrm{~m}$. As shown in Fig. 4, the proportion of the shaded areas strongly decreases in the Innsbruck area from approximately $30 \%$ (for $50 \mathrm{~m}$ and $100 \mathrm{~m}$ resolution) to $15 \%$ and $5 \%$ for resolutions of $400 \mathrm{~m}$ and $800 \mathrm{~m}$ respectively. At the same time there is a flattening of the topography. A strong reflection by unshaded pixels facing the direct sun may lead to such an increase in irradiance. In the Sonnblick area, altitude and changes in the horizon are more affected by the DEM resolution than in Innsbruck. Figure 13 shows an increase in UV in Kolm Saigurn with increasing DEM pixel size with a maximum of approximately $11 \%$ at $400 \mathrm{~m}$ DEM pixel size. The strong increase in altitude at the bottom of the very narrow valleys surrounding Sonnblick (like in Kolm Saigurn) may strongly affect the average albedo and the reflections in the surrounding of Kolm Saigurn and lead to this increase in UV. Together these results show that for stations that are not in the shade changes in UV irradiance are not comparable to the changes in UV shown in Sect. 3.2.1 for shaded areas.

\subsubsection{Influence of digital elevation map resolution on accuracy of UV actinic flux calculations}

The influence of DEM pixel size on the actinic flux in the Innsbruck area is shown for the 56.9 and 70 degree solar zenith angles in Figs. 14 and 15, respectively. A good agreement between model and measurements is only obtained for Innsbruck 12:30 UTC (Fig. 14). For Innsbruck 08:20 UTC model calculations underestimate actinic flux for Hafelekar and partly for Innsbruck and Lans. For the simulation for Sonnblick and surroundings there is a strong underestimation of the calculated actinic flux for Kolm Saigurn. The explanation lies probably in the fact that local factors (reflections

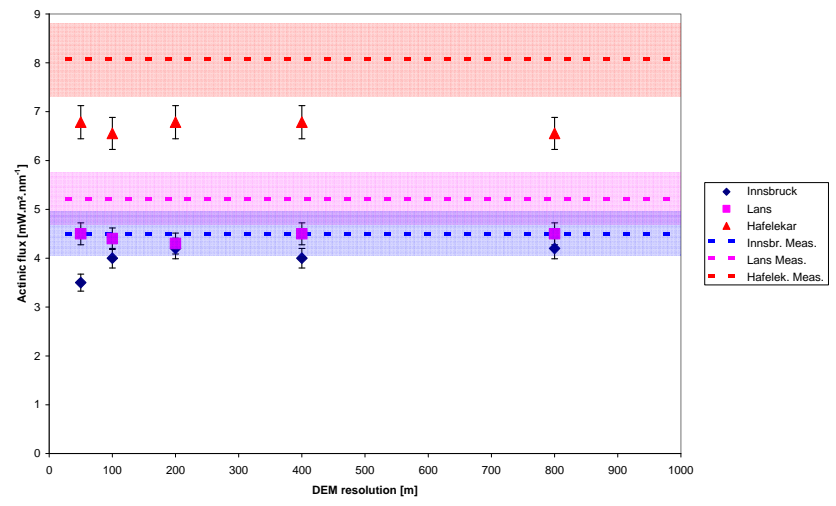

Fig. 15. Modeled 3-D UV Actinic $(305 \mathrm{~nm})$ calculations for 24 February, 08:20 UTC as a function of DEM resolution. Dotted lines show the measurements (interpolation of measurements before and after 08:20 UTC) which correspond to the locations and the time of calculation. Solar zenith angle is 70.0 degree. The shapes show the model results (diamond = Innsbruck, square = Lans, triangle $=$ Hafelekar). The error bars show the accuracy of the model simulations $( \pm 5 \%)$. The coloured areas around the lines of measurements indicate the measurement uncertainty $(= \pm 10 \%)$.

from surrounding objects and from the topography) have a strong influence on the measured actinic flux. For the 56.9 degree solar zenith angle there is an increase in the actinic flux at Innsbruck of up to $12 \%$ (for the $800 \mathrm{~m}$ DEM pixel size compared to $50 \mathrm{~m}$ DEM pixel size calculation). For the other stations the fluctuations are within model accuracy. For the 70 degree solar zenith angle the increase in the actinic flux at Innsbruck is up to $20 \%$ and even larger than for 56.9 degree solar zenith angle. Since actinic flux strongly depends on reflection from the surroundings the decrease of shaded pixels in the surroundings of valley stations may explain this strong increase in actinic flux. The calculations for the region around Sonnblick (Fig. 16) - our third case study - show a steep increase in actinic flux with increasing DEM grid size at Kolm Saigurn which is a very steep valley station. The increase in actinic flux is in the order of $15 \%$. These calculations are made for a solar zenith angle of 32.7 degree. The percentage of the pixels in the shade is already below $10 \%$ for a pixel size of $50 \mathrm{~m}$. At larger DEM grid sizes there are no shaded areas left. This effect obtained in Kolm Saigurn is only possible because of the very pronounced topography in this region.

\section{Discussion and conclusions}

In this work, the influence of DEM pixel size on the calculation accuracy of a 3-D radiative transfer model was investigated in great detail. Model simulations were performed for three case studies in the areas around Innsbruck and the Sonnblick observatory, Austria. As shown in Sect. 3.1.1 differences in the DEM resolution may cause the modeled 


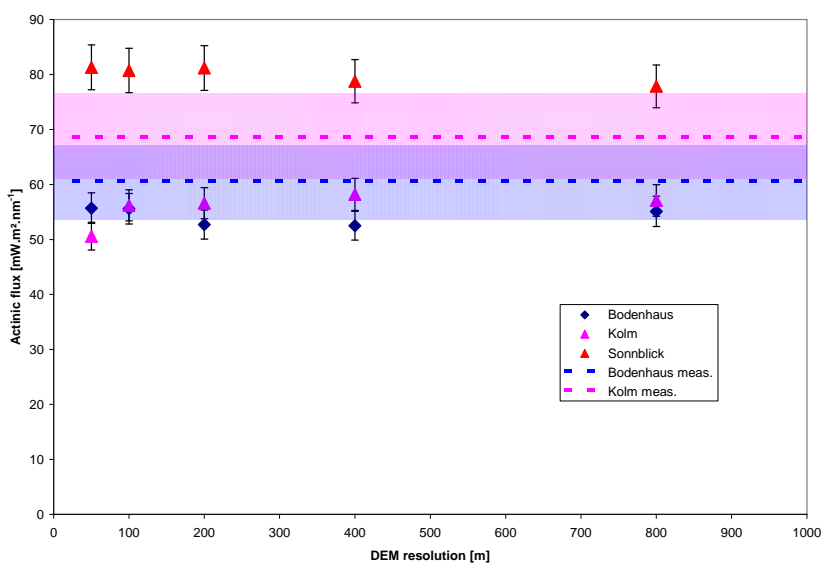

Fig. 16. Modeled 3-D UV Actinic ( $305 \mathrm{~nm}$ ) calculations for 7 May, 12:00 UTC as a function of DEM resolution. Dotted lines show the measurements which correspond to the locations and the time of calculation. Solar zenith angle is 32.77 degree. The shapes show the model results (diamond $=$ Bodenhaus, square $=$ Kolm Saigurn, triangle $=$ Sonnblick). The error bars show the accuracy of the model simulations $( \pm 5 \%)$. The coloured areas around the lines of measurements indicate the measurement uncertainty $( \pm 10 \%)$.

altitude at some locations to vary by up to $500 \mathrm{~m}$, as well as causing changes in sky obscured by the horizon of up to $15 \%$. These alone may lead to an increase of irradiance and actinic flux at $305 \mathrm{~nm}$ of up to $12 \%$. The geographical distribution of UV irradiance and actinic flux shows that with larger pixel size, uncertainties in UV and actinic flux determination of up to $100 \%$ may occur. These large changes in incident irradiance and actinic flux with changing pixel size are strongly connected with the percentage of shaded area. Increasing pixel size is equivalent to flattening out pixel sized areas, and to diminishing height differences between pixels, leading to a reduction in shaded pixels of up to $85 \%$.

We investigated the effect of DEM pixel size on the irradiance (incident on a horizontal plane) and actinic flux for all three case studies. In these case studies all the stations were in direct sunlight. The comparison between model calculations and measurements taking into account the measurement and modelling uncertainties did not show any dependence of the measurement-modelling discrepancy on DEM resolution.

We however found statistical significant differences between some of the model simulations performed for the different DEM resolutions: For the investigation of DEM pixel size on irradiance for Innsbruck and surroundings we did not find any effect on irradiance at noon, but an increase was found for the station at Innsbruck at $400 \mathrm{~m}$ and $800 \mathrm{~m}$ DEM resolution at 08:20 UTC. We also found an increase in simulated irradiance at Hafelekar for DEM pixel size larger than $100 \mathrm{~m}$ also at 08:20 UTC. During these two case studies we also found that for the Innsbruck actinic flux calculation the uncertainty increased with increasing DEM pixel size leading to calculated actinic flux values that were too high by up to $20 \%$ (if we assume that the $50 \mathrm{~m}$ pixel size calculation represents the correct "accurate" reference"). For the Sonnblick case, where the topography is more pronounced, but where the simulations were performed for a solar zenith angle of 32.7 degrees, we found an effect of pixel size on irradiance calculation uncertainty for the valley station Kolm Saigurn with irradiance values too high by $11 \%$ at larger DEM pixel sizes. For the actinic flux, Kolm Saigurn is also affected by changes in DEM pixel size. An increase in actinic flux of approximately $15 \%$ was obtained for DEM pixel size larger than $100 \mathrm{~m}$. Increases in irradiance at Hafelekar are probably due to albedo effects in connection with a significant increase in altitude leaving the valley bottoms in the sun. The changes in the actinic flux and irradiance at valley stations may be connected to reflection from the surrounding pixels, with three factors which may be of importance: the number of non shaded pixels in the surroundings and the changes in the horizon and also the inclination of the surrounding pixels.

The DEM resolution required to obtain small uncertainties in 3-D radiative transfer modeling needs to be high enough to represent the local topography adequately. As seen from the comparison of Innsbruck and Sonnblick, the effect of misrepresenting the topography in the DEM is site, and also SZA dependent. The larger the SZA and the steeper the local topography, the greater the DEM resolution required.

\section{Appendix A}

\section{Calculation of irradiance in the 3-D model}

The pixel discontinuity problem needs to be addressed because large changes in pixel discontinuity with changing DEM resolution are expected.

The 3-D model calculates the number of photons incident on each pixel. It differentiates between photons that have already undergone one scattering event (diffuse flux) and photons that have not had a scattering event (direct flux).

For the model simulations described in Sect. 3.2. the pixels containing the Innsbruck, Hafelekar, Lans, Kolm Saigurn, Bodenhaus and Sonnblick sites are set to a horizontal position in order to be comparable with the input optics of the instruments measuring the irradiance at those locations.

\section{The incident irradiance at one pixel is calculated using the following equation:}

For the direct irradiance

$I_{\text {rea }}=N_{\text {rea, }, \mathrm{dir}} \cdot K \cdot \varepsilon_{\text {dir }}$

where $I_{\text {rea }}\left(\mathrm{W} \mathrm{m}^{-2} \mathrm{~nm}^{-1}\right)$ is equal to the real direct irradiance incident at this pixel (which is the final result of the model simulation). $N_{\text {rea,dir }}\left(1 \mathrm{~m}^{-2}\right)$ corresponds to the number of "direct" photons incident per unit area on this pixel for 
real conditions (with atmosphere). $K\left(\mathrm{~W} \mathrm{~nm}^{-1}\right)$ is the energy conversion factor and $\varepsilon_{\text {dir }}$ (no unit) is the error in counted photons for the direct irradiance (due to pixel discontinuity).

For the diffuse irradiance the following equation is used

$D_{\text {rea }}=N_{\text {rea,dif }} \cdot K \cdot \varepsilon_{\text {dif }}$

where $D_{\text {rea }}\left(\mathrm{W} \mathrm{m}^{-2} \mathrm{~nm}^{-1}\right)$ is equal to the real diffuse irradiance incident at this pixel (which is the final result of the model simulation). $N_{\text {rea,dif }}\left(1 \mathrm{~m}^{-2}\right)$ corresponds to the number of "diffuse" photons incident on this pixel for real conditions (with atmosphere). $K\left(\mathrm{~W} \mathrm{~nm}^{-1}\right)$ is the energy conversion factor and $\varepsilon_{\text {dif }}$ (no unit) is the error in counted photons for the diffuse irradiance (due to pixel discontinuity).

\section{Conversion of photon number to irradiance in $\left(\mathbf{W} /\left(\mathbf{m}^{-2} \mathbf{n m}^{-1}\right)\right)$ : determination of $\mathbf{K}$}

At the top of the atmosphere each photon has a specific amount of energy. The number of photon per $\mathrm{m}^{2}$ on a plane perpendicular to the direct beam is proportional to the power of the sun per $\mathrm{m}^{2}$. If the angle of incidence of the sun changes, the same energy will be projected onto a larger horizontal area and the plane perpendicular to the solar photons which enter into the box is reduced, that means that the same number of photons correspond to a smaller amount of solar power. This relationship is also called Lambert cosine law.

Using the fact that the number of photon per unit area is proportional to the power of the sun per $\mathrm{m}^{2}$ it can be stated that when the solar beam enters the atmosphere:

$P_{\mathrm{tot}} \cdot K / A_{\mathrm{tot}}=I_{\mathrm{ext}} \cdot \cos (\mathrm{sza}) \cdot C_{\mathrm{sun}-\text { earth }}$

where $P_{\text {tot }}$ (no unit) is the total number of photons used in the calculation, $A_{\text {tot }}$ is the total projected horizontal surface of the domain $\left(\mathrm{m}^{2}\right), I_{\mathrm{ext}}$ is the extraterrestrial irradiance in $\left(\mathrm{W} \mathrm{m}^{-2} \mathrm{~nm}^{-1}\right)$, sza is the solar zenith angle, $C_{\text {sun-earth }}$ is the correction factor to take into account the earth sun distance. $K$ is the energy conversion factor (the energy per photon) in $\left(\mathrm{W} \mathrm{m} \mathrm{mm}^{-1}\right.$ ).

In the end we can write

$K=I_{\mathrm{ext}} \cdot \cos (\mathrm{sza}) \cdot C_{\mathrm{sun}-\mathrm{earth}} \cdot A_{\mathrm{tot}} / P_{\mathrm{tot}}$

In the atmosphere photons can undergo several processes (scattering, reflection, absorption), and the model takes this atmospheric extinction into account by diminishing the photon energy and introducing some decimal numbers of photon (e.g., from the original one photon sent through the atmosphere only $30 \%$ of the photon $(=0.3)$ will be arriving at the ground). This will affect the factors $N_{\text {rea,dir }}$ and $N_{\text {rea,dif }}$ (Eqs. (1) and (2)).

\section{Correction for the pixel discontinuity factor $\left(\varepsilon_{\mathrm{dif}}, \varepsilon_{\mathrm{dir}}\right)$}

To determine the error in the number of incident photons at one pixel (due to pixel discontinuity) we need to be able to measure this error.

For the determination of pixel discontinuity error at one pixel we can run one model calculation using ideal conditions (assuming ground is flat so no pixel discontinuity is possible)

Then the effect of topography can be taken into account if the inclination of the pixel (for calculation of $\varepsilon_{\text {dir }}$ of $\varepsilon_{\text {dif }}$ ) and of the sky obscured by the horizon (for calculation of $\varepsilon_{\mathrm{dif}}$ ) are included.

First we can state:

$\varepsilon_{\text {dir }}=N_{p m, d i r} / N_{\text {rea,dir }}$

$N_{\text {pm,dir }}$ is the number of "direct" photons that would be calculated for this pixel (which we call pixel $\mathrm{x}$ ) with the same inclination for a "perfect" model without discontinuities. As already mentioned above, this simulation may be performed by assuming only one plane with the same inclination and orientation than pixel $\mathrm{x}$. We remove an uncertainty which may arise by small altitude differences during the calculations of $N_{\text {pm,dir }}$ and $N_{\text {rea,dir }}$ by performing these simulations without atmosphere.

In this case we can write

$\varepsilon_{\text {dir }}=N_{\text {pm,dir,noA }} / N_{\text {rea,dir,noA }}$

where index noA indicates that the calculation is performed without any atmosphere.

Since the number of total photons $P_{\text {tot }}$ will be evenly distributed over the whole domain

$N_{\text {pm,dir,noA }}=P_{\text {tot }} / A_{\text {tot }}$

$A_{\text {tot }}$ is the total surface of the domain $\left(\mathrm{m}^{2}\right)$.

Therefore

$\varepsilon_{\text {dir }}=P_{\text {tot }} /\left(N_{\text {rea,dir,noA }} \cdot A_{\text {tot }}\right)$

For the calculation of $\varepsilon_{\text {dif }}$ we can use a similar method than for the direct beam correction:

$\varepsilon_{\text {dif }}=N_{\text {pm,dif,noA }} / N_{\text {rea,dif,noA }}$

For the calculation of $N_{\mathrm{pm} \text {,dif, noA }}$ we need to exclude the pixel discontinuity error, that means we need to perform a simulation first for a flat surface (note: the "real" effect of obstruction of the horizon on the counted number of photons will be included later). We simulated diffuse irradiance by using an option in the GRIMALDI code to send isotropic radiation (that means that photons are coming randomly from the upper hemisphere) to the ground. In order to remove multiple scattering effects and reflections from the surroundings, simulations are performed without any atmosphere and ground reflectivity (i.e., ground albedo is set to 0 ). 
Since the number of total photons $P_{\text {tot }}$ will be evenly distributed over the whole domain

We can write:

$N_{\mathrm{pm}, \mathrm{dif}, \mathrm{noA}}=P_{\mathrm{tot}} / A_{\mathrm{tot}}$

$A_{\text {tot }}$ is the total surface of the domain $\left(\mathrm{m}^{2}\right)$.

To include the effects of the horizon we have to multiply $N_{p m, d i f, n o A}$ with a factor $H$ which accounts for the obstruction of the sky by the horizon. $\mathrm{H}$ is the integral over the solid angles of the sky hemisphere

$H=\frac{1}{\pi} \int_{0}^{2 \pi} \int_{0}^{\pi / 2} \sin \theta \cdot \cos \theta \cdot f \cdot d \theta \cdot d \omega$

where $\theta$ is the elevation angle of the solid angle and $\omega$ the azimuth angle. $f$ is a simple numerical factor to account for the sky covered by the horizon. If the obstruction is larger than $\theta, f$ equals 0 , if the angle subtended by the obstruction is smaller than $\theta f$ is equal 1. If no obstruction of the sky by the horizon occurs $f$ is always equal 1 , and therefore also the integral is equal $\pi$ and $H$ is equal 1. $f$ is calculated prior to the calculation of $H$ by a FORTRAN program which calculates if the horizon covers the sky for each azimuth angle taking into account the surrounding pixels altitude and the central pixel inclination and orientation. It works using a virtual beam which "scans" the horizon over the whole $360^{\circ}$ azimuth range.

We can now write using Eqs. (9) and (10):

$\varepsilon_{\text {dif }}=P_{\text {tot }} \cdot H /\left(N_{\text {rea,dif,noA }} \cdot A_{\text {tot }}\right)$

\section{Calculation of direct irradiance $I_{\text {rea }}$ in $\left(\mathrm{W} \mathrm{m}^{-2} \mathrm{~nm}^{-1}\right)$}

If we include Eq. (4) and (8) in Eq. (1) we obtain the final equation for the calculation of the direct irradiance at the ground:

$I_{\text {rea }}=N_{\text {rea,dir }} \cdot\left(I_{\text {ext }} \cdot \cos (\right.$ sza $\left.) \cdot C_{\text {sun- earth }} \cdot A_{\text {tot }} / P_{\text {tot }}\right)$

$\cdot P_{\text {tot }} /\left(N_{\text {rea,dir,noA }} \cdot A_{\text {tot }}\right)$

And therefore

$I_{\text {rea }}=N_{\text {rea,dir }} \cdot\left(I_{\text {ext }} \cdot \cos (\mathrm{sza}) \cdot C_{\text {sun-earth }}\right) / N_{\text {rea,dir,noA }}$

\section{Calculation of diffuse irradiance $D_{\text {rea }}$ in $\left(\mathrm{W} \mathrm{m}^{-2} \mathrm{~nm}^{-1}\right)$}

If we include Eqs. (4) and (12) in Eq. (2) we obtain:

$$
\begin{aligned}
& D_{\text {rea }}=N_{\text {rea,diff }} \cdot\left(I_{\text {ext }} \cdot \cos (\mathrm{sza}) \cdot C_{\text {sun-earth }} \cdot A_{\text {tot }} / P_{\text {tot }}\right) \cdot P_{\text {tot }} \\
& \cdot H /\left(N_{\text {rea, dif,noA }} \cdot A_{\text {tot }}\right)
\end{aligned}
$$

We therefore derive

$D_{\text {rea }}=N_{\text {rea, diff }} \cdot H \cdot I_{\text {ext }} \cdot \cos (\mathrm{sza}) \cdot C_{\text {sun-earth }} / N_{\text {rea,dif,noA }}$
Acknowledgements. This work was financed by the Austrian Science Fund (FWF) within the project "Investigation of actinic flux in mountainous areas under cloudless conditions", project number: P18780-N13.

Edited by: E. Gerasopoulos

\section{References}

Anderson, G., Clough, S., Kneizys, F., Chetwynd, J., and Shettle, E.: AFGL Atmospheric Constituent Profiles (0-120 km), Tech. Rep. AFGL-TR-86-0110, AFGL (OPI), Hanscom AFB, MA 01736, USA, 1986.

Arola, A., Lindfors, A., Natunen, A., and Lehtinen, K. E. J.: A case study on biomass burning aerosols: effects on aerosol optical properties and surface radiation levels, Atmos. Chem. Phys., 7, 4257-4266, doi:10.5194/acp-7-4257-2007, 2007.

Badosa, J., McKenzie, R. L., Kotkamp, M., Calbo, J., Gonzalez, J. A., Johnston, P. V., O'Neill, M., and Anderson, D. J.: Towards closure between measured and modelled UV under clear skies at four diverse sites, Atmos. Chem. Phys., 7, 2817-2837, doi:10.5194/acp-7-2817-2007, 2007.

Bais, A. F., Gardiner, B., Slaper, H., Blumthaler, M., Bernhard, G., McKenzie, R., Webb, A. R., Seckmeyer, G., Kjelstad, B., Koskela, T., Kirsch, P. J., Gröbner, J., Kerr, J. B., Kazadzis, S., Leszczynski, K., Wardle, D., Brogniez, C., Josefsson, W., Gillotay, D., Reinen, H., Weihs, P., Svenoe, T., Eriksen, P., Kuik, F. and Redondas, A.: The SUSPEN intercomparison of ultraviolet spectroradiometers, J. Geophys. Res., 106, 12 509-12 525, 2001.

Bais, A. F., Madronich, S., Crawford., J., Hall, S. R., Mayer, B., Van Weele, M., Lenoble, J. Calvert,J. B., Cantrell, C. A., Shetter, R. E., Hofzumahaus, A., Koepke, P., Monks, P. S., Frost, G., McKenzie, R., Krotkov, N., Kylling, A., Swartz, W. H., Lloyd, S., Pfister, G., Martin, T. J., Roeth, E.-P., Griffioen, E., Ruggaber, A., Krol, M., Kraus, A., Edwards, G. D., Mueller, M., Lefer, B. L., Johnston, P., Schwander, H., Flittner, D., Gardiner, B. G., Barrick, J., and Schmitt, R.: International Photolysis Frequency Measurement and Model Intercomparison (IPMMI): Spectral actinic solar flux measurements and modeling, J. Geophys. Res., 108, 8543, doi:10.1029/2002JD002891, 2003.

Balis, D. S., Amiridis, V., Zerefos, C., Kazantzidis, A., Kazadzis, S., Bais, A. F., Meleti, C., Gerasopoulos, E., Papayannis, A., Matthias, V., Dier, H., and Andreae, M. O.: Study of the effect of different type of aerosols on UV-B radiation from measurements during EARLINET, Atmos. Chem. Phys., 4, 307-321, doi:10.5194/acp-4-307-2004, 2004.

Blumthaler, M. and Amback, W.: Solar UVB-albedo of various surfaces, Photochem. Photobiol., 48, 85-88, 1988.

Blumthaler, M., Ambach, W., Cede, A., and Staehelin, J.: Attenuation of erythemal effective irradiance by cloudiness at low and high altitude in the Alpine region, Photochem. Photobiol., 63, 193-196, 1996.

Cahalan, R. F., Oreopoulos, L., Marshak, A., Evans, K. F., Davis, A., Pincus, R., Yetzer, K., Mayer, B.,Davies, R., Ackerman, T., Barker, H., Clothiaux, E., Ellingson, R., Garay, M., Kassianov, E., Kinne, S., Macke, A., Ohirok, W., Partain, P., Prigarin, S., Rublev, A., Stephens, G., Szczap, F., Takara, E., Varnai, T., Wen, G., and Zhuravleva, T.: The International Intercomparison of 3D 
Radiation Codes (I3RC): Bringing together the most advanced radiative transfer tools for cloudy atmospheres, B. Am. Meteor. Soc., 86, 1275-1293, 2005.

Calbo, J., Pages, D., and Gonzalez, J.-A.: Empirical studies of cloud effects on UV radiation: a review, Rev. Geophys., 43, 155-183, 2005.

Commission Internationale de l'Eclairage (CIE): 134/1, TC 6-26 Report: Standardization of the terms UV-A1, UV-A2 and UV-B, in Collection in Photobiology and Photochemistry, Comm. Int. de l'Eclairage, Vienna, Austria, 1999.

Dahlback, A. and Stamnes, K.: A new spherical model for computing the radiation field available for photolysis and heating at twilight, Planetary and Space Science (ISSN 0032-0633), 39, 671683, doi:10.1016/0032-0633(91)90061-E, 1991.

Degünther, M., Meerkötter, R., Albold, A., and Seckmeyer, G.: Case study on the influence of inhomogeneous surface albedo on UV irradiance, Geophys. Res. Lett. 25, 3587-3590, 1998.

Den Outer, P. N., Slaper, H., and Tax, R. B.: UV radiation in the Netherlands: Assessing long-term variability and trends in relation to ozone and clouds, J. Geophys. Res., 110, D02203, doi:10.1029/2004JD004824, 2005.

Den Outer, P. N., Slaper, H., Kaurola, J., Lindfors, A., Kazantzidis, A., Bais, A. F., Feister, U., Junk, J., Janouch, M., and Josefsson, W.: Reconstructing of erythemal ultraviolet radiation levels in Europe for the past 4 decades, J. Geophys. Res., 115, D10102, doi:10.1029/2009JD012827, 2010.

Feister, U. and Grewe, R.: Higher UV radiation inferred from low ozone levels at northern mid-latitudes in 1992 and 1993, Global Planet, Change, 11, 25-34, 1995.

Gantner, L., Winkler, P., and Köhler, U.: A method to derive longterm time series and trends of UV-B radiation (1968-1997) from observations at Hohenpeissenberg (Bavaria), J. Geophys. Res., 105, 4879-4888, doi:10.1029/1999JD900907, 2000.

Gueymard, C.: Prediction and validation of cloudless shortwave solar spectra incident on horizontal, tilted, or tracking surfaces, Solar Energy, 82, 260-271, 2008.

Hegglin, M. I. and Shepherd, T. G.: $\mathrm{O}_{3}-\mathrm{N}_{2} \mathrm{O}$ correlations from the Atmospheric Chemistry Experiment: Revisiting a diagnostic of transport and chemistry in the stratosphere, J. Geophys. Res., 112, D19301, doi:10.1029/2006JD008281, 2007.

Kalliskota, S., Kaurola, J., Taalas, P., Herman, J. R., Celarier, E., and Krotkov, N.: Comparison of the daily UV doses estimated from Nimbus7/TOMS measurements and ground-based spectroradiometric data, J. Geophys. Res., 105, 5059-5067, doi:10.1029/1999JD900926, 2000.

Kaurola, J., Taalas, P., Koskela, T., Borkowski, J., and Josefsson, W.: Long-term variations of UV-B doses at three stations in northern Europe, J. Geophys. Res., 105, 20813-20820, doi:10.1029/2000JD900258, 2000.

Kazadzis, S., Bais, A. F., Balis, D., Zerefos, C. S., and Blumthaler, M.: Retrieval of down-welling UV actinic flux density spectra from spectral measurements of global and direct solar UV irradiance, J. Geophys. Res., 105, 4857-4864, 2000.

Krotkov, N. A., Bhartia, P., Herman, J., Fioletov, V., and Kerr, J.: Satellite estimation of spectral surface UV irradiance in the presence of tropospheric aerosols 1. Cloud-free case, J. Geophys. Res., 103, 8779-8793, 1998.

Krzyscin, J. W. and Puchalski, S.: Aerosol impact on the surface UV radiation from the ground-based measurements taken at
Belsk, Poland, 1980-1996, J. Geophys. Res., 103, 16175-16181, doi:10.1029/98JD00899, 1998.

Kylling, A., Albold, A., and Seckmeyer, G.: Transmittance of a cloud is wavelength-dependent in the UV-range: Physical interpretation, Geophys. Res. Lett., 24, 397-400, 1997.

Kylling, A., Persen, T., Mayer, B. and Svenoe, T.: Determination of an Effective Spectral Albedo from ground based global and direct UV irradiance measurements, J. Geophys. Res., 105, 4949-4959, 2000.

Kylling, A., Dahlback, A., and Mayer, B.: The effect of clouds and surface albedo on UV irradiances at a high latitude site, Geophys. Res. Lett., 27, 1411-1414, doi:10.1029/1999GL011015, 2000.

Kylling, A., Webb, A. R., Kift, R., Gobbi, G. P., Ammannato, L., Barnaba, F., Bais, A., Kazadzis, S., Wendisch, M., Jäkel, E., Schmidt, S., Kniffka, A., Thiel, S., Junkermann, W., Blumthaler, M., Silbernagl, R., Schallhart, B., Schmitt, R., Kjelstad, B., Thorseth, T. M., Scheirer, R., and Mayer, B.: Spectral actinic flux in the lower troposphere: measurement and 1-D simulations for cloudless, broken cloud and overcast situations, Atmos. Chem. Phys., 5, 1975-1997, doi:10.5194/acp-5-1975-2005, 2005.

Lindfors, A. and Vuilleumier, L.: Erythemal UV at Davos (Switzerland), 1926-2003, estimated using total ozone, sunshine duration, and snow depth, J. Geophys. Res., 110, D02104, doi:10.1029/2004JD005231, 2005.

Longstreth, I., De Gruijl, F. R., Kripke, M. L., Abseck, S., Arnold, F., Slaper, H., Velders, G., Takizawa, Y. and Van der Leun, J. C.: Health risks, J. Photochem. Photobiol. B, 46, 20-33, 1998.

Madronich, S.: Photodissociation in the Atmosphere: 1. Actinic Flux and the Effects of Ground Reflections and Clouds, J. Geophys. Res., 92, 9740-9752, 1987.

Mayer, B. and Kylling, A.: Technical note: The libRadtran software package for radiative transfer calculations - description and examples of use, Atmos. Chem. Phys., 5, 1855-1877, 2005,

http://www.atmos-chem-phys.net/5/1855/2005/.

Mayer, B., Kylling, A., Madronich, S. and Seckmeyer, G.: Enhanced absorption of UV radiation due to multiple scattering in clouds: Experimental evidence and theoretical explanation, J. Geophys. Res. 103, 31 241-31 254, 1998.

Mayer, B., Hoch, S. W., and Whiteman, C. D.: Validating the MYSTIC three-dimensional radiative transfer model with observations from the complex topography of Arizona's Meteor Crater, Atmos. Chem. Phys., 10, 8685-8696, doi:10.5194/acp-10-86852010, 2010.

McKenzie, R. L., Paulin, K. J. and Madronich, S.: Effects of snow cover on UV irradiance and surface albedo: A case study, J. Geophys. Res., 103, 785-792, 1998.

McKenzie, R., Seckmeyer, G., Bais, A., Kerr, J., and Madronich, S.: Satellite retrievals of erythemal UV dose compared with groundbased measurements at northern and southern midlatitudes, J. Geophys. Res., 106, 24051-24062, 2001.

Nader, J. S. and White, N.: Volumetric measurement of ultraviolet energy in an urban atmosphere, Environ. Sci. Technol., 3, 848854, 1969.

National Radiological Protection Board: Health effects from ultraviolet radiation, Report of an advisory group on non-ionising radiation, Doc. NRP, 13, p. 1, UK, 2002.

Pachard, E., Lenoble, J., Brogniez, C., Masserot, D., and Bocquet, J. L.: Ultraviolet spectral irradiance in the French Alps: Results of two campaigns, J. Geoph. Res., 104, 16777-16784, 1999. 
Reuder, J. and Schwander, H.: Aerosol effects on UV radiation in nonurban regions, J. Geophys. Res., 104, 4065-4077, 1999.

Ricchiazzi, P. and Gautier, C.: Investigation of the effect of surface heterogeneity and topography on the radiation environment of Palmer Station, Antarctica, with a hybrid 3-D radiative transfer model, J. Geoph. Res., 103, 6161-6176, 1998.

Rieder, H. E., Holawe, F., Simic, S., Blumthaler, M., Krzyscin, J. W., Wagner, J. E., Schmalwieser, A. W., and Weihs, P.: Reconstruction of erythemal UV-doses for two stations in Austria: a comparison between alpine and urban regions, Atmos. Chem. Phys., 8, 6309-6323, doi:10.5194/acp-8-6309-2008, 2008.

Rieder, H. E., Staehelin, J., Weihs, P., Vuilleumier, L., Maeder, J. A., Holawe, F., Blumthaler, M., Lindfors, A., Peter, T., Simic, S., Spichtinger, P., Wagner, J. E., Walker, D., and Ribatet, M.: Relationship between high UV-doses, total ozone, surface albedo and cloudiness: An analysis of 30 years of data from Switzerland and Austria, Atmos. Res., 98, 9-20, 2010.

Sabburg, J. M., Parisi, A. V., and Kimlin, M. G.: Enhanced spectral UV irradiance: a 1 year preliminary study, Atmos. Res., 66, 261272, 2003.

Schafer, J. S., Saxena, V. K., Wenny, B. N., Barnard, W., and De Luisi, J. J.: Observed influence of clouds on ultraviolet-B radiation, Geophys. Res. Lett., 23, 2625-2628, 1996.

Scheirer, R. and Macke, A.: On the accuracy of the independent column approximation in calculating the downward fluxes in the UVA, UVB, and PAR spectral ranges. J. Geophys. Res., 106, 14301-14312, 2001.

Scheirer, R. and Macke, A.: Cloud inhomogeneity and broadband solar fluxes. J. Geophys. Res., 108, 4599, doi:10.1029/2002JD003321, 2003.

Schmalwieser, A. W., Schauberger, G., Weihs, P., Simic, S., Stubi, R., Janouch, M., and Coetzee, G. J. R.: Preprocessing of total ozone content as an input parameter to UV index forecast calculations, J. Geophys. Res. 108, 4176-4189, 2003.

Schmucki, D. A. and Philipona, R.: Ultraviolet radiation in the alps: The altitude effect, Opt. Eng., 41, 3090-3095, 2002.

Schwander, H., Koepke, P., and Ruggaber, A.: Uncertainties in modeled UV irradiances due to limited accurancy and availability of input data, J. Geophys. Res., 102, 9419-9430, doi:10.1029/97JD00244, 1997.

Seckmeyer, G., Erb, R., and Albold, A.: Transmittance of a cloud is wavelength-dependent in the UV-range, Geophys. Res. Lett., 23, 2753-2755, 1996.

Simic, S., Weihs, P., Vacek, A., Kromp-kolb, H., and Fitzka, M.,: Spectral UV measurements in Austria from 1994 to 2006: Investigations of short- and long-term changes, Atmos. Chem. Phys., 8, 7033-7043, doi:10.5194/acp-8-7033-2008, 2008.

Simic, S., Fitzka, M., Schmalwieser, A., Weihs, P., and Hadzimustafic, J.: Factors affecting UV irradiance at selected wavelengths at Hoher Sonnblick, Atmos. Res., 101, 869-878, doi:10.1016/j.atmosres.2011.05.022, 2011.

Slaper, H., Velders, G. J. M., Daniel, J. S., De Gruijl, F. R., and Van der Leun, J. C.: Estimates of ozone depletion and skin cancer incidence to examine the Vienna Convention achievements, Nature, 384, 256-258, 1996.

Smith, R.C., Wan, Z., and Baker, K. S.: Ozone depletion in Antarctica: modeling its effect on solar UV irradiance under clear-sky conditions, J. Geophys. Res. 97, Issue C5, 7383-7397, 1992.

Smolskaia, I., Nunez, M., and Kelvin, M.: Measurements of Erythe- mal Irradiance near Davis Station, Antarctica: Effect of Inhomegeneous Surface Albedo, Geoph. Res. Lett., 26, 1381-1384, 1999.

Smolskaia, I., Masserot, D., Lenoble, J., Brogniez, C., and De La Casiniere, A.: Retrieval of the ultraviolet effective snow albedo during 1998 winter campaign in the French Alps, Appl. Opt., 42, 1583-1587, 2003.

Staiger, H., Den Outer, P. N., Bais, A. F., and Vuilleumier, L.: Hourly resolved cloud modification factors in the ultraviolet, Atmos. Chem. Phys., 8, 2493-2508, doi:10.5194/acp-8-2493-2008, 2008.

Thiel, S., Steiner, K., and Seidlitz, H. K.: Modification of global erythemally effective irradiance by clouds, Photchem. Photobiol., 65, 969-973, 1997.

Thiel, S., Ammannato, L., Bais, A., Bandy, B., Blumthaler, M., Bohn, B., Engelson, E., Gobbi, G. B., Gröbner, J., Jäkel, E., Junkermann, W., Kazadzis, S., Kift, R., Kjelstad, B., Kouremeti, N., Kylling, A., Mayer, B., Monks, P. S., Reeves, C. E., Schallhart, B., Scheirer, R., Schmidt, S., Schmitt, R., Schreder, J., Silbernagl, R., Topaloglou, C., Thorseth, T. M., Webb, A. R., Wendisch, M., and Werle, P.: Influence of clouds on the spectral actinic flux density in the lower troposphere (INSPECTRO): overview of the field campaigns, Atmos. Chem. Phys., 8, 17891812, doi:10.5194/acp-8-1789-2008, 2008.

United Nations Environment Program (UNEP): Environmental effects of ozone depletion: 1998 assessment, Nairobi, Kenya, 1998.

Vanicek, K., Frei, T., Litynska, Z., and Schmalwieser, A.: UV-index for the public: A guide for publication and interpretation of solar UV index forecasts for the public prepared by theWorking Group 4 of the COST-713 action "UVB forecasting", Eur. Coop. Field Sci. Tech. Res., Brussels, 2000.

Van Weele, M., De Arellano, J. V.-G., and Kuik, F.: Combined measurements of UV-A actinic flux, UV-A irradiance and global radiation in relation to photodissociation rates, Tellus, 47B, 353364, 1995.

Wagner, J. E, Angelini, F., Arola, A., Blumthaler, M., Fitzka, M., Gobbi, G. P., Kift, R., Kreuter, A., Rieder, H. E., Simic, S., Webb, A., and Weihs, P.: Comparison of surface UV irradiance in mountainous regions derived from satellite observations and model calculations with ground based measurements. Met. Zeitschr., 19, 481-490, 2010.

Wagner, J. E, Angelini, F., Blumthaler, M., Fitzka, M., Gobbi, G. P., Kift, R., Kreuter, A., Rieder, H. E., Simic, S., Webb, A., and Weihs, P.: Investigation of the 3-D actinic flux field in mountainous terrain. Atmos. Res., 102, 300-310, 2011.

Webb, A. B., Bais, A. F., Blumthaler, M., Gobbi, G. P., Kylling, A., Schmitt, R., Thiel, S., Barnaba, F., Danielsen, T., Junkermann, W., Kazantzadis, A., Kelly, P., Kift, R., Liberti, G. L., Misslbeck, M., Schallhart, B., Schreder, J., and Topaloglou, C.: Measuring spectral actinic flux and irradiance: Experimental results from the Actinic Flux Determination from Measurements of Irradiance (ADMIRA) project, J. Atmos. Ocean Technol., 19, 1049-1062, 2002.

Weihs, P. and Webb, A.: Accuracy of spectral UV model calculations: 2 - Comparison of UV calculations with measurements, J. Geophys. Res., 102, 1551-1560, doi:10.1029/96JD02621, 1997.

Weihs, P., Simic, S., Laube, W., Mikielewicz, W., Rengarajan, G., and Mandl, M.: Albedo influences on surface UV irradiance at 
the Sonnblick High Mountain Observatory (3106 m altitude), J. Appl. Met., 38, 1599-1610, 1999.

Weihs, P., Lenoble, J., Blumthaler, M., Martin, T., Seckmeyer, G., Philipona, R., De La Casiniere, A., Sergent, C., Gröbner, J., Cabot, T., Masserot, D., Pichler, T., Pougatch, E., Rengarajan, G., Schmucki, D., and Simic, S.: Modelling the effect of an inhomogeneous surface albedo on incident UV radiation in mountainous terrain: Determination of an effective surface albedo, Geophys. Res. Lett., 28, 3111-3114, doi:10.1029/2001GL012986, 2001.
Wenny, B. N., Schafer, J. S., De Luisi, J. J., Saxena, V. K., Barnard, W. F., Petropavlovskikh, I. V., and Vergamini, A. J.: A study of regional aerosol radiative properties and effects on ultraviolet-B radiation, J. Geophys. Res., 103, 17083-17097, 1998.

World Health Organization (WHO): Global Solar UV Index - A practical guide, 2002.

World Health Organization (WHO): Environmental Burden of Disease Series No. 13 - Solar Ultraviolet radiation, 2006. 